\title{
Arte popular criativa e turismo cultural na cidade de Loulé (Algarve/Portugal)
}

\author{
Creative folk art and cultural tourism in the city of Loulé \\ (Algarve/Portugal)
}

\section{Arte popular creativa y turismo cultural en la ciudad de Loulé (Algarve/Portugal)}

\section{Jean Carlos Vieira Santos ${ }^{1}$ João Albino Silva²}

\begin{abstract}
Resumo: Este trabalho aborda a arte popular criativa como oferta complementar ao produto "turismo cultural" em espaço urbano, uma experiência que tem como chave interpretativa o descobrimento das reflexões e interpretações acerca da inovação estratégica do produto artesanal na cidade de Loulé, na região Algarve, em Portugal. Sob esse pressuposto, interessa-nos aqui não a descrição dos artesãos e artesanatos, mas a discussão acerca da relação entre arte popular e criatividade, uma abordagem integrada nas tendências do turismo cultural. Nesse contexto, o artigo traz o exemplo do projeto de Técnicas Ancestrais e Soluções Atuais (TASA). Desse modo, considera-se como método a subjetividade das entrevistas e dos trabalhos de campo, por meio dos quais foi possível observar as situações do cotidiano, os espaços e lugares dos artesãos com sua arte popular criativa. $O$ texto traz argumentos e análises acerca do turismo nos contextos cultural e criativo e na experiência de valorização da arte popular em Loulé.
\end{abstract}

Palavras-chave: Turismo Cultural. Arte Popular. Criatividade. Cidade de Loulé.

Abstract: This work approaches the creative folk art as a complementary offering to the product "cultural tourism" in urban space, an experience that has the unraveling of reflections and interpretations about the strategic innovation of craft products in the city of Loulé, in Algarve region, in Portugal, as an interpretive key. By this assumption, we are not interested in a description of artisans and crafts, but in the discussion about the relationship between folk art and creativity, an integrated approach in the trends of cultural tourism. In this context, the article offers the example of Ancestral Techniques and Current Solutions (ATCS) project. Thus, we consider the subjectivity of interviews and fieldwork as a method, and, through those ones, we observed everyday situations, spaces and places of artisans with their creative folk art. Therefore, the text brings arguments

\footnotetext{
${ }^{1}$ Professor Doutor do Curso de Geografia da Universidade Estadual de Goiás (UEG). Quirinópolis, Goiás, Brasil. Email: Jean.vieira@ueg.br

2 Professor catedrático da Faculdade de Economia (FE) da Universidade do Algarve (UALG). Diretor do Programa de Doutoramento em Turismo da FE da UALG. Investigador do Centro de Investigação do Espaço e das Organizações (CIEO). Faro, Algarve, Portugal. E-mail: jsilva@ualg.pt
} 
and analysis about tourism in the cultural and creative contexts and in the experience of valorization of folk art in Loulé.

Keywords: Cultural Tourism. Folk Art. Creativity. City of Loulé.

Resumen: En este trabajo se aborda el arte popular creativo como una oferta complementaria al producto "turismo cultural" en el espacio urbano, una experiencia cuya clave interpretativa se desentraña las reflexiones e interpretaciones de la innovación estratégica de los productos artesanales en la ciudad de Loulé, en la región Algarve en Portugal. Bajo este supuesto, no nos interesa aquí una descripción de los artesanos y artesanías, pero la discusión sobre la relación del arte popular y la creatividad, un enfoque integrado en las tendencias del turismo cultural. En este contexto, el artículo ofrece el ejemplo del proyecto de Técnicas Ancestrales y Soluciones Actuales (TASA). Por lo tanto, se considera como un método de la subjetividad de entrevistas y trabajo de campo y, a través de ellos, observamos situaciones cotidianas, espacios y lugares de artesanos con su arte popular creativo. Por lo tanto, el texto aporta argumentos y análisis sobre el turismo en los contextos culturales y creativos en la experiencia de valorización del arte popular en Loulé.

Palabras clave: Turismo Cultural. Arte Popular;. Creatividad. Ciudad de Loulé.

\section{INTRODUÇÃO}

A arte popular criativa, como oferta complementar ao produto "turismo cultural" em espaço urbano, é uma atividade social e econômica que tem assumido relevância nas primeiras décadas do século XXI, sobretudo em cidades turísticas, numa lógica de renovação de territórios culturais, de arranjos dos espaços públicos, de valorização e requalificação de antigos bairros ou setores particulares da cidade. Os contributos positivos do desenvolvimento da arte popular criativa para os núcleos urbanos turísticos estão também associados à criação de melhores condições de vida para os artesãos tradicionais e contemporâneos do lugar.

De acordo com Richards (2011), as pessoas parecem cada vez mais interessadas em desenvolver o seu potencial criativo, melhorando as suas habilidades produtivas ou de consumo, além de procurar cursos ou experimentar a criatividade de férias. Em estudos sobre economias urbanas, o turismo criativo tem sido colocado como uma extensão do turismo cultural; uma economia de experiências em que a cultura se torna um instrumento para o crescimento e desenvolvimento.

Nesse contexto, o presente artigo aborda uma experiência que tem como chave interpretativa o desdobramento das reflexões e interpretações acerca da inovação estratégica do produto artesanal na cidade de Loulé, na região Algarve, em Portugal, na perspectiva de sua valorização, identificação, contextualização e reinvenção da arte popular com uma componente criativa associada ao turismo cultural. Esse processo de transubstanciação é relevante por, a partir da arte popular de diferentes sujeitos, se configurar como uma atividade criativa complementar ao turismo cultural, com produtos que trazem necessidades contemporâneas e comerciais em suas marcas. 
Sob esse pressuposto, não nos interessa aqui a descrição dos artesãos e artesanatos de Loulé, mas a discussão acerca da relação entre arte popular e criatividade, com uma abordagem integrada nas tendências do turismo cultural. Desse modo, será sublinhada a olaria presente em toda a região Algarve, uma paisagem de confinamento de elementos e investimentos que a define como destino turístico maduro e internacional. Nesse sentido, pode-se considerar que o "confinamento territorial do turismo pode ser entendido como uma extensão contínua de interesses, microcosmos, no perímetro dos quais tem de se dar a vida turística" (Yázigi, 1998, p. 41).

Nesse viés, Ribeiro (1986), um especialista dedicado ao estudo geográfico português, caracteriza a paisagem algarvia por meio da tradição árabe, salientando que esses povos reforçaram o tom mediterrâneo regional e que historicamente foram mais polidos. Outra concepção a assinalar diz respeito ao fato de, na referida região, haver cidades com arquiteturas, monumentos e vestígios de romanos, visigóticos e árabes. Santos (2013, p. 105), afirma que os árabes foram "os responsáveis pelo nome regional Algarve, cuja denominação Al-Gharb, significa Ocidente".

O encadeamento geográfico deste artigo tem como escala de análise a cidade de Loulé que, por sua vez, pertence ao distrito de Faro e é sede do maior e mais populoso município da região Algarve, com uma população de 70.163 habitantes (INE), com área de $763,67 \mathrm{~km}^{2}$. Tem seus limites geográficos com Silves, Almodôvar, Alcoutim, Tavira, São Braz do Alportel, Faro, Albufeira e Oceano Atlântico, e é subdividido em nove freguesias. O município engloba duas cidades, Loulé e Quarteira, com destaque para os complexos turísticos Vilamoura/Quarteira, Quinta do Lago e Vale do Lobo.

Diante do objetivo central apresentado, deve-se fazer, ainda nesse ponto, uma breve referência a Santos (2011). Convém salientar que o artesanato é a mais pura manifestação de arte popular criativa conduzida por mãos hábeis, quase sempre desconhecidas, que operam em consonância com o gosto e a intuição do artista nato, cujas aprendizagem e maturidade são colhidas na escola da vida, em que o aluno é o professor de si próprio.

$\mathrm{O}$ artesanato é uma prática social e cultural, assim como uma das criações humanas que são construídas a partir de um modo de vida, em que as pessoas do lugar que estão envolvidas encontram condições de se constituir como seres sociais, de enfrentar suas dificuldades cotidianas e de reproduzir suas humanidades (Santos \& Silva, 2016). Nesse viés, pode-se dizer que 0 :

[...] artesanato é técnica e trabalho do artesão; arte de fazer objeto. [...] é uma atividade que exige esforço físico e intelectual, pois é uma lógica que dá forma a objetos que saem do imaginário de sujeitos que tem seu conhecimento extraído de hábitos do cotidiano. É permeado de uma série de valores que juntam sua concepção e o contexto em que é produzido (Santos \& Silva, 2016, p.111-112).

Para Coriolano (2009, p.160), o artesanato “[...] pode ser direcionado para atividade turística, como forma de valorização do patrimônio cultural e das representações culturais do povo". Os autores Santos e Silva (2015) conceituam os trabalhos artesanais como valo- 
res, práticas, costumes e culturas elaboradas por diferentes grupos de famílias, com marcas que identificam a região.

Com base nesses apontamentos, não se pode deixar de reconhecer que os artesãos são sujeitos sensibilizados que se fazem presentes em contextos e lugares bastante particulares, singulares e sob uma perspectiva única de viver o artesanato. "São, porquanto, pessoas sensíveis à confecção de objetos que outros deixaram marginalizados ao longo do tempo" (Santos \& Silva, 2015, p. 685). Esse modo de pensar leva a definir que:

O artesão é o produto mais acabado de quando pode a imaginação humana no domínio do trabalho manual. Tudo o que é produzido pelo homem, neste campo, tem arte, até aquilo que o próprio homem, nas suas exigências estéticas e superrefinadas, queira entender que o não é (Santos, 2011, p. 471).

Há tempos que o ser humano se realiza espiritualmente na confecção de objetos de uso pessoal e outros utensílios exigidos (e aperfeiçoados) pelo seu cotidiano. O homem, por natureza e analisado em termos genéricos, é um artesão, um artista popular, dada a capacidade que possui de poder conciliar e adaptar o pensamento aos movimentos certos e harmoniosos de mãos criativas. Possui imaginação, gosto e habilidade manual.

Nas regiões, emergem-se paisagens, territórios, lugares e cidades turísticas, em que há um visitante cada vez mais culto, atento, observador e interessado pelas artes populares criativas e cultura de base local. Esse turista busca, nas obras dos artistas-artesãos do lugar, sinais de identidade e particularidades que não são globais, além de diferenças e um produto único, dando valor a uma singularidade da paisagem visitada, uma tendência e componente do turismo cultural.

Nesses termos, o presente trabalho apresentará uma experiência denominada projeto de Técnicas Ancestrais e Soluções Atuais (TASA), uma proposta de desenvolvimento integrado da cultura artesanal no município de Loulé e região Algarve. Contudo, essa discussão necessita não somente de entendimento das ações desenvolvidas, mas também de uma abordagem teórica sobre a complexidade e as densidades inerentes ao turismo cultural e à arte popular criativa.

Vale ressaltar que o Algarve, que já foi romano e árabe, possui uma pluralidade de culturas e trabalhos artesanais em que o olhar do turista para sua arte popular é como se ela fosse o espelho das comunidades que formam as diferentes paisagens da região. São práticas culturais que ultrapassam as fronteiras nacionais e enriqueceram o cotidiano de diferentes camadas sociais que viajam pelo mundo. É, porquanto, uma componente complementar não só ao produto "turismo cultural", mas também ao produto "sol e praia", que é a principal oferta do destino turístico internacional Algarve.

\section{TURISMO NOS CONTEXTOS CULTURAL E CRIATIVO: UMA ABORDAGEM PRELIMINAR}

No senso comum, a cultura popular pode ser compreendida como algo que acontece espontaneamente, pela habilidade de mãos criativas dentro de um conjunto de ações e 
imaginários que constituem o cotidiano. Ela pode ser vista como um fio condutor para o entendimento da sociedade, uma vez que "é na vida cotidiana que acontecem as verdadeiras criações, as ideias, os valores, os costumes. Os sentimentos expressam-se no cotidiano" (Lefebvre, 1991, p. 27). Portanto, é diariamente que sujeitos artesãos populares criam peças utilitárias, decorativas ou lúdicas que se tornam espelho da comunidade, fazendo parte da cultura do lugar.

Em muitas cidades, essa arte popular torna-se uma oferta complementar ao produto "turismo cultural", contribuindo com o desenvolvimento econômico e social de base local. Assume-se relevância nos meios urbanos, como o caso de Loulé no Algarve português, que se mostra como um produto turístico específico, cheio de particularidades e com grandes potencialidades.

Conforme Santos (2006), pode-se afirmar que o reconhecimento da heterogeneidade cultural dá origem, do ponto de vista dos estudos geográficos, turísticos e econômicos, ao fato de formas particulares da cultura popular se relacionarem com especificidades de tempo e de lugar. Nesse caso, as potencialidades da abordagem cultural contribuem para enfatizar o significado dos lugares e o conceito de espaço vivido, algo feito a partir das experiências e descobertas pessoais e da dimensão simbólica da vida.

A partir disso, surgem estudos acerca dos lugares e territórios de artesãos, que destacam as representações inseridas nos processos e dinamismos que estão na gênese do turismo cultural. Aportando nessa vertente teórica, pode-se dizer que a cultura popular é constituída pelo conjunto mediador de instrumentos (utensílios e demais materiais) e pelas normas que regem os diversos grupos sociais (ideias, artesanatos, crenças e costumes), advindos dos signos criados pelo homem (Zuin \& Zuin, 2009).

Ao se considerar a cultura, seja ela simples ou complexa, estaremos sempre em presença de um vasto aparato material. Juntamente com o surgimento da cultura popular nasceram:

[...] as tradições, a fim de que ajudassem o homem a transmitir os saberes construídos historicamente. Tais tradições buscavam ainda preservar a história particular de uma família, de uma geração, de uma região e de um país. Desta forma, o homem também inventou as tradições, utilizando a história como amálgama para a interação e coesão social entre eles. (Zuin \& Zuin, 2009, p. 80).

Para os autores citados, o conceito de tradição está intimamente ligado à história de uma cultura. A tradição se manifesta por meio de valores, crenças e rituais transmitidos e conservados de geração em geração por meio de relações de ensino e aprendizagem. Como uma forma de perpetuar conceitos e experiências, o trabalho do artesão é uma tradição popular que deve ser analisada em seu contexto local, pois é um elemento constitutivo da cultura, paisagem e das relações de aprendizado em diferentes contextos, locais e regionais. De acordo com os interesses de órgãos públicos e privados, pode-se tornar uma componente cultural do turismo urbano. 
No entanto, existe hoje uma cultura planetária que promove novas relações com o tempo, o passado e o território. Essa cultura apela à experiência, a uma atração quase nostálgica, a uma identidade social e territorial; logo, "os sítios, os lugares, os territórios, adquirem novas dimensões, simbólicas e afetivas" (Cravidão, 2014, p. 59). Porém, no contexto espacial local, as cidades, as paisagens e os lugares abrigam diferentes trabalhos de artesãos que formam a cultura popular de base local e até mesmo regional. São caracterizados, em geral, por peças de barro de oleiros, cestarias, teares, etc.

Diante disso, o turismo se coloca como um fenômeno civilizacional suportado por cultura, história, povos, língua, trabalho artesanal e por um sistema de símbolos e valores, mas que em suas contradições envolve a produção e o consumo. De fato, o turismo deve ser visto "no âmbito de um paradigma moderno de gestão e planejamento de pessoas, do patrimônio, da cultura". (Costa, Brandão \& Costa, 2014, p. 13).

Vale lembrar que o turismo cultural "[...] é todo turismo no qual o principal atrativo não é a natureza, mas um aspecto da cultura humana, que poderá ser a história, o cotidiano, o artesanato ou qualquer dos aspectos abrangidos pelo conceito de cultura" (Barretto, 2007, p. 87). Medina e Santamarina (2004, p. 64), por exemplo, dizem que o turismo cultural "[...] es un puente de comunicación y entendimiento entre culturas y pueblos, un factor de comprensión directa de la diversidad cultural para las personas, visitantes y visitados". Enquanto isso, Barretto (2007, p. 84) elucida que:

O turismo cultural surge como uma alternativa por tratar-se de um turismo de minorias, cujos protagonistas, que seriam turistas não institucionalizados, experimentais, experienciais e existenciais, são mais educados e respeitam o meio ambiente natural e cultural. $O$ turismo cultural, de acordo com essas premissas, teria menos efeitos negativos nos núcleos receptores.

Nesse sentido, a obra de Fayos-Solà e Jafari (2009, p. 160) ajuda a compreender que o turismo cultural deve "[...] respetar la autenticidad sociocultural de las comunidades anfitrionas, conservar sus activos culturales, arquitectónicos y vivos y sus valores tradicionales, y contribuir al entendimiento y a la tolerancia interculturales". Por conseguinte, as ligações entre turismo cultural e territórios, paisagens, região e lugares:

[...] parecem-nos particularmente importantes no tecido das práticas turísticoculturais da sociedade contemporânea. É neste sentido que as novas cumplicidades entre turista/visitante e o lugar representam, para a sociedade contemporânea, um elo entre a tradição e a modernidade e, por isso, uma ligação em construção permanente. (Cravidão, 2014, p. 60).

Conforme a obra citada, vale salientar que o turismo cultural é um território de memórias, materiais e imateriais, além de uma teia de contradições. Para muitos, a viagem continua a ser um emaranhado de fronteiras entre o imaginário e o concreto, entre o real e a ficção, em que o lugar adquire cada vez mais um valor simbólico - nesse entremeio, o turismo cultural urbano ainda é um campo completamente aberto para se desenvolver. 
Diante dessa potencialidade espacial aberta ao turismo cultural são apontados outros olhares mais complexos que incluem a análise pautada na sustentabilidade sociocultural: "Las bases generadoras del turismo sostenible deben identificarse en pilares sólidos, que garanticen procesos continuados e integrales" (Fayos-Solà \& Jafari, 2009, p. 161).

Cunha (2001) inclui no turismo cultural as viagens provocadas pelo desejo de ver coisas novas, de aumentar os conhecimentos, conhecer as particularidades e os hábitos de outros povos, conhecer civilizações e culturas diferentes, do passado e do presente. Pode-se afirmar que a cultura popular foi, desde sempre, um dos mais importantes fatores de desenvolvimento do turismo que se torna cada vez mais acentuado.

Grande parte das viagens é realizada para destinos que dispõem de fatores culturais notáveis, tais como os locais históricos, monumentos, centros arqueológicos, centros de peregrinação, concentrações de caráter étnico, arte oleira, entre outros. Alguns desses fatores podem ser criados artificialmente em qualquer parte (caso dos museus), mas outros estão profundamente ligados aos locais onde se desenvolveram (locais históricos ou centros arqueológicos, por exemplo), e há ainda aqueles que se relacionam à maneira de viver de cada povo, como os saberes tradicionais por meio de obras artesanais, com uma abordagem integrada à arte popular.

Dessa maneira, "a cultura e os bens culturais exercem uma forte atração podendo, por si sós, dar origem à criação de destinos turísticos" (Cunha, 2001, p. 122). Nesse contexto, basta dizer simplesmente que, no início do século XXI, novos estudos sobre o turismo cultural mostram uma nova realidade a ser abordada, associando-a à nova classe média para ser conhecida como classe criativa, consumidora do turismo cultural criativo.

De acordo com Ferreira (2014, p. 86), a classe criativa "contribui, de forma decisiva, quer para o surgimento das cidades, vilas e aldeias criativas, quer para o desenvolvimento do designado turismo criativo". As características específicas desse segmento de mercado trouxeram para o centro do debate não só a problemática da co-criação - a qual perpassa atualmente, de modo transversal, muitas áreas do saber -, mas também a necessidade de valorizar a criatividade e a inovação como fatores críticos de desenvolvimento e agentes primordiais da distinção dos destinos turísticos.

A nova classe média valoriza os produtos de massa e os de cultura popular ou os de alta cultura, porque domina uma vasta gama de competências culturais desde os saberes que exigem pouca ou nenhuma mediação até aos associados a um elevado grau de formalismo - essa nova classe emerge como a mais importante consumidora de turismo cultural (Ferreira, 2014). Em algumas cidades surgiram bairros culturais e de entretenimento definidos como uma área geográfica que contém a maior:

[...] concentração de equipamentos culturais e de entretenimento - teatros, cinemas, estúdios, galerias de artes, salas de concertos, livrarias, cafés e restaurantes. Os projetos de regeneração urbana através da cultura e do turismo, favoráveis à formação dos bairros culturais, surgiram um pouco por toda a Europa, nos anos de 1990. Neste novo contexto, a cultura englobava a valorização das artes e indústrias culturais, o reconhecimento da diversidade cultural, do multiculturalismo, a que se 
associava o apreço pós-moderno pela imagem e pelo caráter simbólico dos locais (Ferreira, 2014, p. 88).

Uma das características mais marcantes da relação entre arte popular e criatividade está na experiência vivenciada pelo município de Loulé, no destino turístico internacional Algarve, em Portugal. Nessa cidade, as artes populares tornaram-se importantes em seus planos de desenvolvimento econômico e de emprego, uma novidade induzida pelo turismo cultural que incrementa não só a dimensão econômica, mas também a social e a cultural. A arte criativa de Loulé baseia-se:

[...] na experiência, participar, aprender (não observar apenas os ícones, ou alguém a pintar ícones, mas antes frequentar um curso sobre pintura de ícones no destino). [...] o turismo criativo é a próxima geração do turismo cultural que satisfaz as necessidades de auto atualização, enfocadas no desenvolvimento das competências, com base em recursos que são processos como dançar, cantar, produzir peças de artesanato, pintar, participar em festivais, evitando, deste modo, os impactos negativos gerados pelo consumo do espaço construído. (Ferreira, 2014, p. 94).

Essa arte popular criativa, na experiência colocada em prática na cidade de Loulé, exige o envolvimento ativo no processo criativo, de modo a estabelecer um engajamento e uma troca com a população e a cultural local. Exige-se, pois, uma relação entre o processo criativo e o destino, ancorando-o na cultura, na criatividade e na identidade popular, além da co-criação entre visitantes e a população local. A experiência co-criativa, ao colocar o turista e o residente como cúmplices, facilita a interação harmônica entre ambos - Sem essa cumplicidade, não existe experiência criativa.

A experiência de desenvolvimento da arte popular criativa como uma componente de desenvolvimento do turismo cultural ajuda a diferenciar produtos do lugar, com base numa identidade de consumo e inovação própria dos locais que desejam cultivar uma imagem de distinção e sofisticação. No cerne da atividade turística está a necessidade de criar uma oferta que corresponda aos estilos de vida dos consumidores.

Para Ferreira (2014), no século XXI, a criatividade e a inovação ganharam uma importância fulcral para a competividade global, posto que as políticas e estratégias urbanas para o desenvolvimento a partir da cultura e do turismo passaram a ser cada vez mais consideradas. De acordo com Richards (2011), o turismo é uma das principais operadoras de crescimento económico no domínio da cultura e criatividade.

Portanto, a virada para a criatividade pode ser vista como uma das mais amplas instrumentalizações da cultura e da criatividade propriamente dita. Ela passou a ser seguida pelas cidades e regiões em busca de crescimento, como uma estratégia de promoção da inovação e desenvolvimento de habilidades populares individuais. Tais modificações podem se relacionar aos processos mais amplos da globalização, mercantilização e crescente concorrência entre cidades e regiões. 
Observamos o desenvolvimento do turismo cultural como um ambiente cada vez mais criativo e lúdico, no qual novas práticas podem ser desenvolvidas desafiando as representações atuais de espaço. $\mathrm{O}$ aumento da criatividade como um fenômeno individual e social tem sido estimulado por processos relacionados à produção e ao consumo (Richards, 2011). Nesse contexto:

The natural and cultural environment has intrinsic value, and is protection and preservation is essential to the long-term success and viability of tourism. The relationship between tourism and the environment, both natural and cultural, must be managed so that it is sustainable in the long-term. [...] Tourism should communicate appropriate cultural and environmental sensitivity. Local involvement in sustainable tourism planning processes is essential in promoting harmony between tourism and the residents (Hovinen, 2006, pp. 80-81).

No tocante ao artesanato e trabalho popular do artesão, é importante destacar que eles são uma manifestação cultural produzida por mãos criativas de diferentes sujeitos num contexto temporal e espacial. A dialética tempo-espaço permite que esse saber fazer popular se modifique a partir do contexto social em que é vivenciado. $O$ artesanato não é algo formado por uma linearidade cultural, pois em destinos turísticos ele supera a barreira do local e se estabelece pelo conjunto de ações que apropria dessa arte e o revela para a rede comercial inseridas no segmento turismo cultural.

Conteúdos, alterações e metamorfoses fazem com que a cultura desenvolvida pelo artesão, assim como suas manifestações simbólicas e modos de vida, se tornem parte do destino turístico - essa arte se comunica com o ambiente e os sujeitos de fora, (re)criando um sistema comercial.

As trocas proporcionadas pelos movimentos comerciais de sujeitos locais e turistas geram movimentos que alteram (de modo mais ou menos visível) as práticas cotidianas no destino. Nesse entremeio, o artesanato e o turismo cultural podem se ligar ao desenvolvimento de novos projetos públicos e privados, a exemplo do TASA desenvolvido na cidade de Loulé.

\section{METODOLOGIA}

O presente trabalho considera como método a abordagem qualitativa de entrevistas e trabalhos de campo em Loulé. Segundo Brandão (2007, p. 12), por mais que um investigador possa utilizar de uma objetividade para seguir um roteiro semiestruturado, "[...] todo trabalho de produção do conhecimento se passa através de uma relação subjetiva. A pessoa que fala, fala para uma outra".

Desse modo, a pesquisa qualitativa é uma linha de investigação que não procura seguir um plano elaborado com rigidez. Tal método é concebido, “[...] principalmente, numa perspectiva compreensiva. A coleta de dados é baseada em métodos que não implicam quantificação e, sim, a interpretação do fenômeno estudado" (Matos \& Pessôa, 2009, p. 
280). As autoras destacam que várias técnicas são utilizadas na investigação qualitativa, como observações, entrevistas, pesquisa-ação, discurso do sujeito coletivo, entre outras.

Este artigo priorizou-se o enfoque da entrevista e observação. Vale salientar que a abordagem não se encontra estruturada em um estudo de caso, mas numa referência cultural que traz elementos importantes para articular a reflexão teórica proposta a uma prática de técnicas ancestrais desenvolvidas na cidade de Loulé. Nas entrevistas, o pesquisador introduziu o assunto, ao passo que os entrevistados, interlocutores responsáveis pelo projeto TASA, tiveram a liberdade de discorrer sobre a questão central aqui abordada.

Por meio do método qualitativo, foi possível observar as situações do cotidiano, os espaços e lugares dos artesãos com sua arte popular criativa, os artesanatos, os gestores do projeto TASA e o turismo cultural no destino Algarve. Portanto, o texto traz argumentos a favor do desenvolvimento integrado da cultura artesanal popular com criatividade, considerando que há importantes traços e bens culturais das populações do interior algarvio; por isso, é necessário colocá-la como relevante instrumento ao serviço do desenvolvimento regional, nomeadamente a partir da promoção de um turismo cultural.

Este artigo é também resultado de uma investigação de fontes escritas, orais e trabaIhos de campo. Uma ordem indispensável para a construção deste se refere às fontes escritas ou pesquisa documental (levantamento das referências), recorrendo aos serviços das bibliotecas da Universidade do Algarve. Essa etapa foi fundamental para a construção teórica; no entanto, constatou-se uma relativa escassez de obras no domínio do artesanato popular com criatividade e turismo cultural, além dessa temática conexa ao desenvolvimento econômico do turismo e patrimônio regional, tendo em vista que, para reduzir a lacuna teórica encontrada, foram fundamentais os trabalhos de campo.

Os trabalhos de campo realizados na cidade de Loulé podem ser considerados, literalmente, uma experiência científica marcante, uma viagem ao lugar de investigação que trouxe sentido, conteúdos, significados e existência a este texto. Pode-se destacar os argumentos de Trigo (2013, p. 139) para dizer que a atividade empírica exige condições especiais, "[...] atitudes e posturas sociais, culturais, estéticas e políticas que permitam uma diferenciação e uma marca".

Ao promover educação e novos conhecimentos, a reflexão trouxe possibilidades multidisciplinares de discussões e análises fecundas, pois colocou os pesquisadores diante do cruzamento das relações socioculturais por meio do trabalho artesanal popular criativo com o espaço algarvio. Durante os trabalhos de campo houve o levantamento fotográfico do recorte de pesquisa e dos espaços do projeto TASA em Loulé.

Um caminho produtivo a ser ressaltado concerne às entrevistas semiestruturadas (fonte oral). De acordo com Silva e Soriano-Sierra (2015, p. 84), essa técnica objetiva "conhecer as percepções, o conhecimento, os anseios, experiências e expectativas"; neste estudo foram entrevistados, numa amostragem não probabilística, os sujeitos responsáveis e envolvidos com o projeto TASA. Foram feitos registros de áudio: 
[...] e transcritos para confiabilidade do estudo, sendo esse fato de plena ciência e concordância do entrevistado [...]. Posteriormente, as entrevistas foram transcritas integralmente para análise e interpretação dos dados segundo o método do Discurso do Sujeito Coletivo (DSC). (Silva \& Soriano-Sierra, 2015, p. 84).

Após as entrevistas, os trabalhos de campo e levantamentos bibliográficos, seguiram-se as análises, a seleção e a consequente estrutura do trabalho. Foi mantido o máximo possível de rigor científico, mas mantendo as expressões e terminologias subordinadas ao tema tratado, o que possibilita leituras e diversas formas de pensar o assunto "arte popular criativa e turismo cultural".

\section{BREVE RESENHA GEOGRÁFICA DO CONCELHO DE LOULÉ NA REGIÃO ALGARVE, EM POR- TUGAL}

Do ponto de vista geográfico, econômico, social e cultural, não é uma tarefa fácil apresentar o concelho de Loulé (Figura 1) separado da região Algarve; por isso, haverá uma abordagem que sublinha as duas realidades ao mesmo tempo. Convém salientar que o Algarve é uma paisagem constituída por 16 municípios (Albufeira, Alcoutim, Aljezur, Castro Marim, Faro, Lagoa, Lagos, Loulé, Monchique, Olhão, Portimão, São Braz de Alportel, Silves, Tavira, Vila do Bispo e Vila Real de Santo Antônio) e 84 freguesias.

No seu diagnóstico regional, a Comissão de Coordenação e Desenvolvimento Regional do Algarve (CCDR Algarve, 2006, p. 13) afirma que essa paisagem corresponde a $5 \%$ do território nacional. Ela está localizada no sul do país, sendo limitada a norte pelo Alentejo, a leste pela província espanhola de Huelva e a sul e oeste pelo Atlântico.

Geofisicamente, o Algarve, bem como o município de Loulé, pode ser dividido em três regiões ou compartimentos: Litoral, Serra e Barrocal. Designa-se barrocal a sub-região formada por calcários, coberta por vegetação tipicamente mediterrânica (Pessoa et al., 2005). Com vistas a situar espacialmente, deve-se salientar que nessa paisagem estão a área urbana de Almancil e as comunidades de Pereiras, Campina de Baixo e Alfarrobeiras. A sede do concelho, o espaço urbano de Loulé, localiza-se nos limites de contatos do Barrocal com a Serra.

Já os compartimentos de serras do Algarve e concelho de Loulé são formados por terrenos antigos (granito típico e sienito), compondo o chamado interior algarvio e classificados pelo poder público regional como área de baixa densidade turística. De acordo com Daveau (1995, pp. 120-121), o terceiro compartimento, isto é, o litoral, é a área de alta densidade turística, caracterizada pela maior presença dos turistas e dos serviços ofertados. Nessa paisagem estão os principais núcleos urbanos turísticos do concelho de Loulé - Quarteira e Vilamoura. 
Figura 1- Região central da cidade de Loulé. Ao fundo, do lado esquerdo da imagem, o mercado público municipal, principal ponto de circulação de turistas

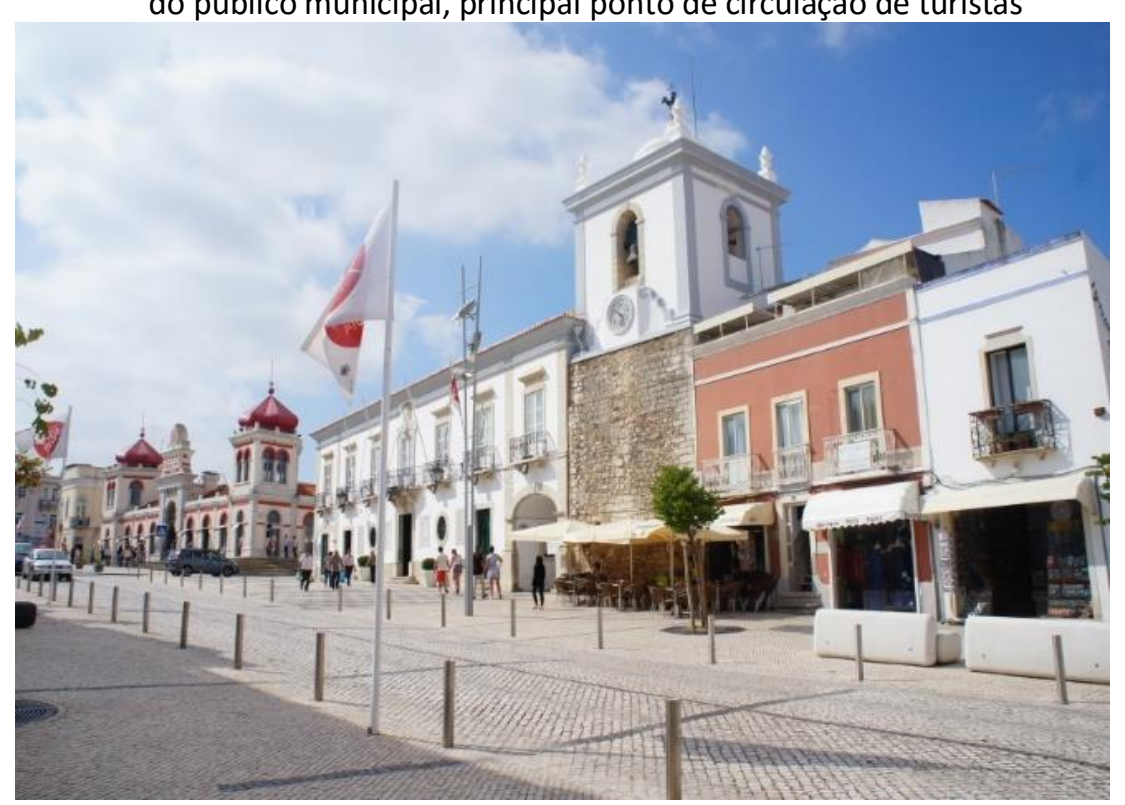

Fonte: Vieira Santos (2014)

No Algarve e no concelho de Loulé, as atividades econômicas assentam-se em três setores-chaves: o turismo, que integra a rede hoteleira e a restauração (bares e restaurantes), a construção civil e o comércio, que são nucleares na região, seja pelo pessoal que empregam ou pela riqueza que geram. No entanto, outras atividades como as ligadas à indústria, agricultura e pesca podem ser destacadas, embora apresentem tendência para a perda de importância relativa à economia regional.

Em relação ao patrimônio cultural do concelho de Loulé, é possível destacar o museu municipal, o polo museológico da cozinha tradicional, a igreja matriz de São Clemente, o centenário mercado municipal, entre outros atrativos abertos à visitação. Verifica-se que o centenário mercado de Loulé, inaugurado no dia 27 de junho de 1908, tornou-se um dos principais atrativos dessa cidade. Em termos arquitetônicos, essa obra adotou o estilo revivalista de inspiração árabe, com quatro pavilhões e quatro portões de acesso.

Com base em Almeida (2013), pode-se afirmar que o mercado muncipal, o artesanato e outros atrativos apresentados são bens culturais de Loulé, pois são produtos de concepção humana, dotados de um valor singular qualquer, seja por constituir uma obra de arte ou por representar um testemunho, um registro ou um documento da história dos homens do lugar. São bens culturais diversos e únicos que representam o saber fazer de uma rica paisagem e compõem o patrimônio cultural regional e local.

Nota-se que o projeto TASA não nasce por simples influência de seus interlocultores, mas por existir matéria-prima em Loulé. Na fase inicial, o projeto contou com os saberes acumulados de 14 artesãos que aceitaram trabalhar nessa parceria de desenvolvimento local. Por essa razão, a cidade investigada aparece como base de uma proposta de desenvolvimento do turismo cultural e criatividade na região Algarve. 


\section{A EXPERIÊNCIA DA CIDADE DE LOULÉ: O DESENVOLVIMENTO INTEGRADO DA CULTURA POPULAR CRIATIVA}

Ao discutir a relação da arte popular com criatividade, como uma componente do turismo cultural urbano, uma lógica que marca esse trabalho é a experiência desenvolvida na cidade de Loulé, denominada projeto TASA. Ele está ancorado nos saberes empíricos e científicos acumulados ao longo dos séculos, com uma perspectiva dinâmica de adaptar antigas técnicas e artefatos às necessidades atuais.

De acordo com a CCDR Algarve (2012, p. 7), os objetivos desse projeto estão "firmemente baseados em técnicas ancestrais que se estão a perder e na linguagem contemporânea acrescentada pela equipe de designer, os produtos do TASA estão a provar ter uma boa aceitação do mercado", conforme a Figura 2.

Figura 2 - Produtos do projeto TASA em exposição para comercialização na loja da ProActiveTur, na cidade de Loulé

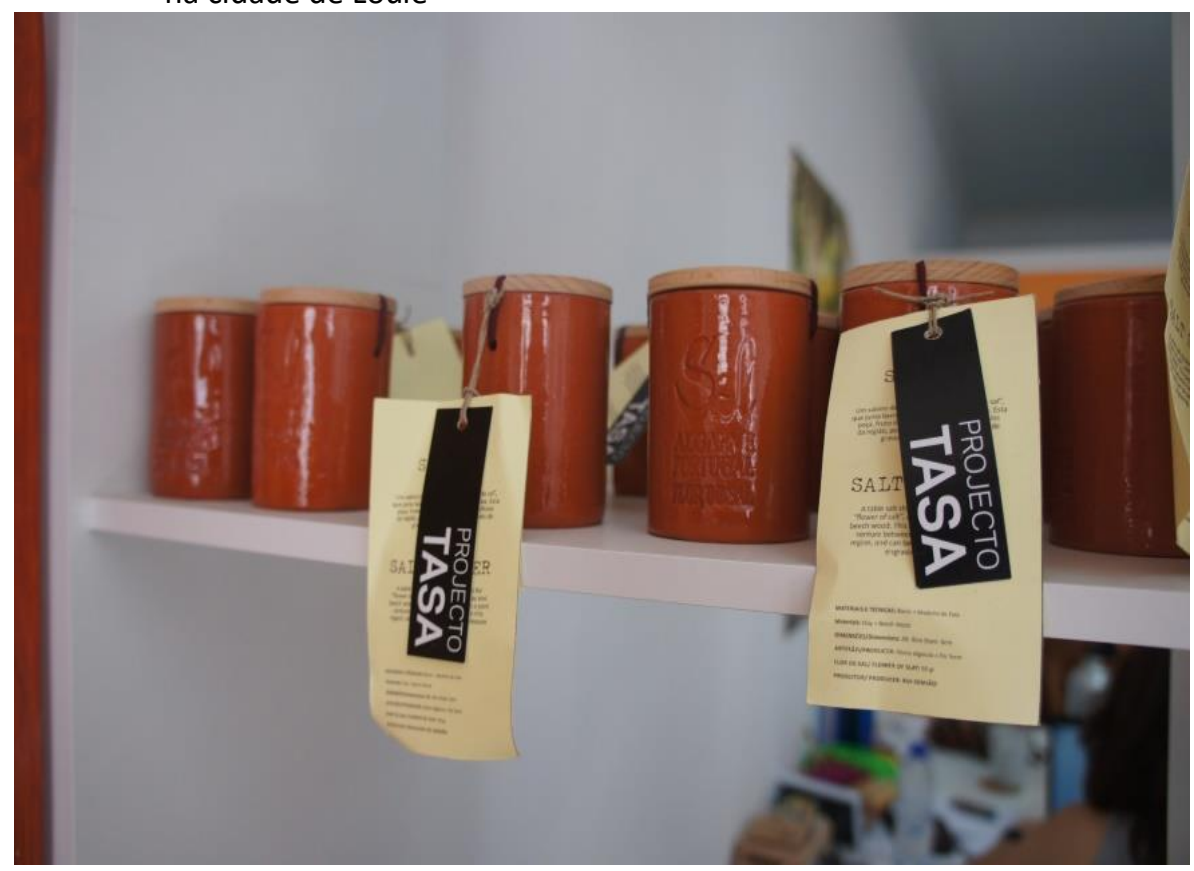

Fonte: Vieira Santos (2014)

Um sujeito entrevistado informou, durante os trabalhos de campo, que:

A CCDR Algarve em 2010 e 2011 lançou esta iniciativa para tentar preservar uma série de artes e ofícios que estavam a desaparecer e estão a desaparecer no Algarve. E aí juntaram um grupo de artesãos de várias áreas, desde a olaria, a empreita, a cestaria, a cortiça e a cana, portanto, juntaram um grupo de artesãos que durante um ano estiveram a trabalhar no desenvolvimento de diferentes peças mais contemporâneas, úteis; que fossem mais facilmente vendidas no mercado, mais aceitas no mercado e que isso fosse um contributo para que as artes não desaparecessem. Porque está aqui um problema grave, complicado de resolver, é que muitas das artes estão a desaparecer, porque hoje as pessoas habituaram sempre a fazer a mesma peça, a mesma peça, e nunca houve evolução. Portanto, a ideia 
do TASA foi criar aqui uma evolução em nível das peças. É para que, de fato, haja uma oportunidade de criar empregos e, sobretudo, envolver jovens. (Entrevista de campo no ano de 2014, com sujeito envolvido com os projetos de turismo na cidade de Loulé, Portugal).

É preciso ressaltar, ainda, que a perda dos saberes e fazeres populares acumulados ao longo de milênios - nomeadamente as artes criativas dos artesãos que não têm sido transmitidas às novas gerações - é um risco que permanece e afeta toda a região Algarve. A aliança dos saberes populares locais sobre materiais e técnicas de produção de artefatos e o design, criando novos produtos com valor comercial acrescido e que contribuam para afirmar a atividade artesanal como uma profissão do futuro, é a ideia-chave do projeto TASA:

Baseado no trabalho em rede dos diversos atores ligados à temática Artesanato, o projeto contou desde o início com uma pareceria alargada entre diversas entidades públicas de âmbito regional, os Municípios, as Associações de Artesãos e as Associações de Desenvolvimento Local. O envolvimento continuado dos diversos segmentos intervenientes-desde logo os artesãos que aceitaram trabalhar durante alguns meses com os designers no sentido de experimentar e introduzir inovações nos seus produtos (CCDR Algarve, 2012, p. 9).

Também se fizeram presentes, nas fases de implantação do projeto, alguns sujeitos jovens que criaram desde artefatos até materiais de comunicação juntamente com artesãos e empresas, os investigadores de diversas instituições regionais que desenvolveram suas histórias a cada produto, além das empresas e associações que contribuíram para a definição das linhas de produtos comercialmente viabilizáveis.

O projeto TASA aporta na vertente do desenvolvimento integrado da cultura popular artesanal na região Algarve. Procura-se "afirmar a identidade própria de um conjunto de atividades artesanais, inerentes a um território, no sentido de construir a valorização da diferença" (CCDR Algarve, 2012, p. 12), a valorização da cultura material regional e, especificamente, do município de Loulé.

Em geral, outro ponto a ser destacado no texto da CCDR Algarve (2012) se refere ao fato de o projeto apostar na promoção do artesanato criativo da região, focando na revalorização da identidade dela, a partir de uma cultura que está imbricada numa atividade que é do lugar, que representa as tradições desse território.

Assim, os sujeitos envolvidos com o TASA esperam que:

A aliança com o design, a aposta na formação, na excelência de todos os atores
envolvidos, no desenvolvimento de novas formas de pensar e potenciar as ativida-
des tradicionais, introduzindo estratégias de projeto e de negócio, e concebendo
estas práticas no âmbito de um território oposto à estandardização e à tipificação
que dominam os nossos dias, certamente introduzirão um valor acrescido ao ofício
e ao objeto manual [...]. (Godinho apud CCDR Algarve, 2012, p. 39).

Participaram do projeto artesãos que desenvolvem sua arte a partir de fibras vegetais, cortiça, olaria (barro) - Figura 3-, cestos com verga de vime, aguardente e licores de medronho, sapataria, tecedeiras, telheiro, brinquedos em madeira, entre outros. 
Figura 3 - Produtos do projeto TASA que associam os trabalhos de artesãos oleiros e da cortiça, dando uma nova imagem à produção artesanal

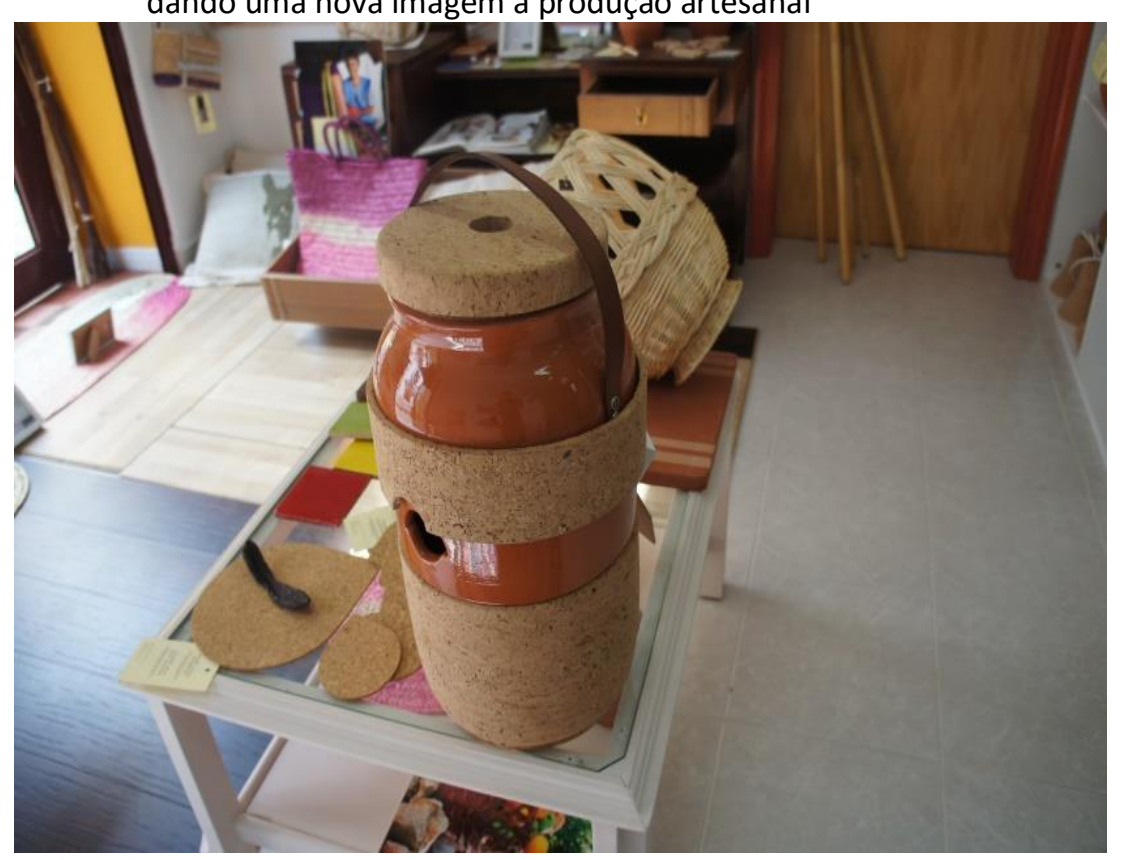

Fonte: Vieira Santos (2014)

Durante um ano (de 2010 a 2011), esses sujeitos trabalharam com a CCDR Algarve no desenvolvimento do projeto e na criação de:

[...] lindíssimos produtos, que são produtos mutantes e que no fundo levaram ao encontro da necessidade do mercado. $\mathrm{E}$ que em alguns casos criaram-se produtos com uma nova imagem, renovada, uma imagem cuidada. E que em alguns casos produtos feitos por mais de um artesão, por exemplo, produtos feitos por um senhor que trabalha a cortiça e por um senhor que trabalha a olaria. Então, os dois participam na mesma peça, que era uma coisa até agora, era muito raro encontrar no Algarve. Isto é uma forma, enfim, do ponto de vista do trabalho cooperativo [...] é interessante, pois eles acabam por estar envolvidos de uma forma mais dinâmica na confecção de peças e nas ideias (Entrevista de campo no ano de 2014, com sujeito envolvido com os projetos de Turismo na cidade de Loulé, Portugal).

Tal projeto implantado em Loulé busca tecer relações vividas no tempo e espaço, que estabelecem o cotidiano e se ligam ao global por meio de conexões e redes, a partir da atividade turística - isso é permeado pela busca do desenvolvimento integrado da cultura artesanal algarvia. Desse modo, faz-se necessário discorrer que a CCDR Algarve gerenciou a fase inicial do projeto TASA (agosto de 2010 a agosto de 2011).

Em 2012, houve uma pausa nas ações e, com o objetivo de retomar os trabalhos, em 2013, a CCDR Algarve abriu licitação para que a segunda fase do projeto TASA fosse gerida por uma empresa privada, desenvolvendo a parte comercial para dinamizar a rede e criar novos produtos. A empresa vencedora foi a ProActiveTur - Turismo Responsável, da cidade de Loulé. Um dos gestores da empresa lembra que: 
Em 2013, nós começamos a gerir o projeto e, desde 2013 até agora, basicamente o que nós fizemos é dinamizar o projeto. É trabalhar com os artesãos; nós estamos sempre a trabalhar com eles. Estamos a comercializar, é uma parte importantíssima vender peças, para que os artesãos obviamente ganhem e nós também, naturalmente. E desenvolver novos produtos, estamos sempre a desenvolver novos produtos (Entrevista de campo no ano de 2014, com sujeito envolvido com projetos na cidade de Loulé, Portugal).

De acordo com o entrevistado durante os trabalhos de campo, os produtos criados na primeira fase tiveram uma saída comercial satisfatória, principalmente os de combinação da olaria com a cortiça (Figura 4) que é vendida, principalmente, para restaurantes, lojas e hotéis em Lisboa e nas cidades do Algarve. Em 2014, iniciaram-se as exportações para países como Japão, Inglaterra e Brasil por meio da internet, utilizando principalmente as páginas de Facebook, os e-mails, sites e blogs.

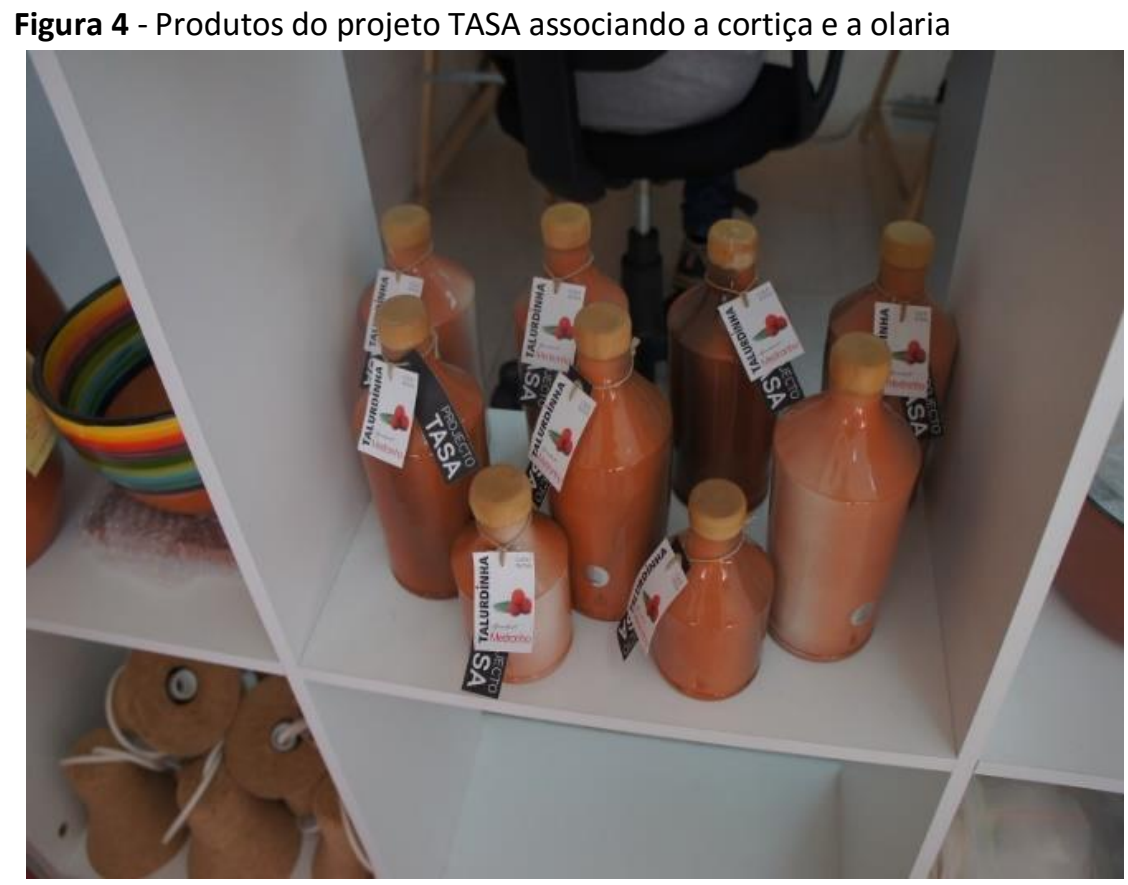

Fonte: Vieira Santos (2014)

De fato, a rede mundial de computadores proporciona a divulgação dos produtos artesanais, mas outros meios também são importantes no processo de marketing e comércio das peças criadas, sobretudo cartazes, folhetos e revistas. A empresa também é contratada por clientes que desejam peças personalizadas e por organizações públicas da região de turismo do Algarve, que compra produtos para colocá-los nos postos de turismo.

Os gestores responsáveis pela segunda fase do projeto TASA tem trabalhado efetivamente com as atividades relacionadas ao turismo cultural, pois percebem que os turistas estão interessados em participar da confecção dos produtos, os artesanatos que desejam adquirir. Esses visitantes que chegam ao Algarve, especialmente a Loulé, estão interessados em: 
[...] meter a mão na massa, né? Ou seja, mexer no barro, aprender a fazer empreita, entretanto começamos a desenvolver uma linha de atividades à volta também do artesanato, então é por isso que estamos no turismo criativo. Então começamos a desenvolver uma série de atividades ligadas ao artesanato, diferentes cursos que tem a ocorrer sempre cheios. Organizamos Seminários de Turismo Criativo e oficinas experimentais. E agora estamos a desenvolver um catálogo, estamos a trabalhar com a Câmara de Loulé também (Entrevista de campo no ano de 2014, com sujeito envolvido com projetos na cidade de Loulé, Portugal).

Esse trabalho desenvolvido por meio de parceria público-privado no concelho de Loulé tem como objetivo principal colocar esse município dentro da rede internacional de turismo criativo, aproveitando a potencialidade à volta das artes e ofícios populares criativos. Entre o ciclo de cursos oferecidos "Iniciação as Artes e Ofícios Tradicionais", estão: trapologia, empreita, lã (técnica do feltro), correeiro, olaria, tecelagem (ciclo do linho) e cestaria. O valor de cada curso fica entre trinta e cinco e quarenta euros.

Conforme o Diário Online (2014, p. 1), o turismo criativo e cultural surge nessa paisagem algarvia como alternativa ao turismo massificado, típico do litoral: "Loulé está a apostar numa oferta diferenciada e tornou-se a primeira cidade portuguesa a integrar a rede mundial de turismo criativo, sendo agora uma cidade amiga da criatividade".

O projeto Loulé Criativo, impulsionado pelos gestores responsáveis pela segunda fase do projeto TASA, objetiva levar os turistas a descobrir e realizar atividades típicas do lugar, envolvendo artistas e atores ligados a artes, ofícios, gastronomia, etc. - a ideia é mostrar aos visitantes o que é genuíno. Por isso, os gestores entrevistados em Loulé consideram o turismo cultural, ligado à arte criativa, uma tendência crescente, mas, para entrar na rede internacional:

[...] de turismo criativo é preciso que as Câmaras Municipais estejam interessadas, né? E que vejam neste tipo de turismo uma oportunidade, porque é algo ainda relativamente novo. Portanto, é preciso que quem está por trás das decisões tenha uma visão ao futuro e que perceba de fato que isso é um misto de etapas que está a crescer. Também é preciso que a oferta esteja estruturada, né? Tem que trabaIhar com os artesãos, com as pessoas; portanto, muitas pessoas com quem nós trabalhamos não são propriamente guias turísticas. O oleiro é oleiro, não é propriamente um agente turístico. Temos que preparar esses artesãos muito bem, e esse trabalho tem que ser feito. Há que estruturar muito bem as atividades, mas, no caso de Loulé, a Câmara viu com bons olhos e está a apostar muito nisso, no turismo cultural criativo (Entrevista de campo no ano de 2014, com sujeito envolvido com projetos na cidade de Loulé, Portugal).

Ademais, a partir das discussões realizadas por Pires, Anjos e Silva (2009), pode-se afirmar que a implementação da atividade turística determina, em maior ou menor grau, o encontro/contato entre turistas e a população local, seja quando "o turista compra um bem ou serviço de um residente, ou quando os dois grupos convivem simultaneamente em territórios turísticos ou, ainda, quando estes estabelecem contato mais estreito pela troca de ideias e informações". (Pires et al., 2009, p. 75). 
Richards (2011) discorre que as práticas de desenvolvimento da produção e do consumo estão na vanguarda do turismo cultural integrando a arte popular criativa, com uma relação simbiótica entre a produção dirigida para o desenvolvimento de novas experiências e consumidores desejosos por novas fontes de diversão e distinção. Em termos de produção, o aumento da criatividade está frequentemente ligado ao desenvolvimento da "economia da experiência". O turismo cultural tornou-se um importante motor desse processo, com o desenvolvimento de ambientes de experiências específicas e a re-embalagem de uma gama de serviços turísticos com "experiências".

Afirma-se que o desenvolvimento do turismo cultural, tendo como componente a arte criativa popular em cidades como Loulé, permite que o contato entre morador e visitante exista e, para além de salvaguardar o artesanato como arte criativa, é necessário que as políticas públicas locais saibam articular as dimensões econômica e turística. Os exemplos mencionados são uma tentativa de explicitar e aumentar o debate acerca da cidade criativa e do turismo cultural criativo, como informação sobre lugares, territórios e paisagens que formam um destino turístico internacional e maduro, como Algarve.

\section{CONSIDERAÇÕES FINAIS}

As entrevistas e discussões que abordam a arte popular criativa como uma componente do desenvolvimento integrado do turismo cultural no destino turístico internacional Algarve, especificando o município de Loulé, mostraram que, para a sua realização e concretização, são fundamentais a intervenção e participação do setor público. Esse agente desempenha um papel central na dinâmica do turismo cultural, a partir da criação e disponibilização de infraestruturas básicas e equipamentos de suporte, bem como nas parcerias desenvolvidas com o setor privado.

Nesse contexto, concorda-se com os entrevistados deste artigo. O turismo cultural na concepção da arte criativa popular é uma tendência crescente no mundo globalizado em rede, por aportar em destinos turísticos maduros como Algarve, buscando promover e reinventar a arte popular conduzida por mãos hábeis e criativas, quase sempre desconhecidas dos visitantes. Essa nova realidade propõe colocar os turistas em consonância com o gosto e a intuição do artista nato, cuja aprendizagem se dá por meio de cursos e oficinas, fortalecendo a internacionalização de uma cultura de base local.

Para os atores envolvidos, os visitantes que se deslocam em busca de conhecimento cultural estão cada vez mais interessados em fazer coisas práticas. Não há apenas o desejo em ver o oleiro trabalhando na roda e de ser um consumidor de suas peças. Esses sujeitos oriundos de outros territórios, interessados em cultura, também buscam aprender com aqueles que são do lugar e veem nesses encontros a possibilidade de uma nova experiência, levando para os lugares de origem alguma arte consigo, para se tornarem um praticante e consumidor do turismo cultural. 
Diante do objeto ora investigado, assevera-se que o espaço urbano de Loulé se afirma como mola dinamizadora da arte popular criativa em Portugal. Tal contexto é importante para que o turismo cultural assuma a função de requalificador do território, apostando na diversificação de atividades populares criativas, que reúnem recursos de variadas ordens, o que permite executar políticas de ofertas complementares ao produto sol e praia na região Algarve. A cidade pesquisada neste trabalho apresenta ainda uma dinâmica própria e capacidade de atrair turistas interessados na arte popular com inovação e criatividade.

Na cidade de Loulé se nota que o turismo cultural é centrado numa motivação com raízes populares e de tradição, conduzido por habilidades e criatividades de artesãos e artistas residentes. É possível discorrer que o projeto TASA é uma tomada de consciência acerca da importância de uma gestão estratégica e planejada que integra a arte popular criativa ao turismo cultural. A existência de produtos de arte popular criativa, com inovação, é uma realidade e oportunidade para organizações culturais e patrimoniais do espaço urbano investigado.

A arte popular criativa, relatada na experiência de Loulé, é um recurso utilizado para dar identidade ao lugar, inserindo-a num contexto de particularidade. Nesses termos, as estratégias locais objetivam incentivar o desenvolvimento do turismo cultural, incluindo a ele um sistema de publicidade e inovação amplamente definido pela arte, artesanato e design.

Essa essência mostra que o destino turístico precisa abordar cuidadosamente os aspectos da criatividade que estão ligados à arte popular do lugar, sendo responsáveis pelas visitas de turistas criativos. Cada local tem um potencial criativo único para oferecer uma combinação de conhecimentos, habilidades, ativos físicos, capital social e atmosfera que tornam certos territórios adequados para determinadas atividades criativas. No que tange à experiência de Loulé, a oferta turística criativa é construída em torno de uma série de cursos e oficinas oferecidos por artesãos locais.

O patrimônio artesanal, se bem valorizado por iniciativas públicas e privadas, é uma potencialidade considerável. Quanto mais bem-sucedido for o trabalho de um artesão, mais visitantes atrairá e maior será o potencial de impacto de sua arte na qualidade cultural e social do destino. Esses fatores poderão atenuar os problemas que acontecem com os ofícios tradicionais que, ao longo dos anos, têm sido negligenciados pelos gestores de destinos turísticos que priorizam segmentos como sol e praia, levando ao desaparecimento de saberes pretéritos que dão identidade a lugares, territórios e regiões.

Enfim, este trabalho, no que tange ao projeto TASA, trouxe reflexões e descobertas, mas também fez surgir várias ideias e aspirações. Nesse sentido, será necessário fazer uma nova leitura daqui a algum tempo, ou seja, avaliar as metas atingidas que foram colocadas em prática e o envolvimento continuado entre as diversas entidades públicas de âmbito municipal e regional, de artesãos e associações de desenvolvimento do turismo e de outros setores econômicos. 


\section{REFERÊNCIAS}

Almeida, Maria Geralda de. (2013). Cultura, paisagem e patrimônio cultural: reflexões desde o Brasil Central. Revista Espaço e Geografia, 16(2), 417-440.

Barretto, Margarita. (2007). Cultura e turismo: discussões contemporâneas. Campinas: Papirus.

Brandão, Carlos R. (2007). Reflexões sobre como fazer trabalho de campo. Revista Sociedade e Cultura, 10(1), 11-27, jan./jun.

CCDR Algarve. Comissão de Coordenação e Desenvolvimento Regional do Algarve. (2012). TASA Técnicas Ancestrais, Soluções Atuais. Loulé: Gráfica Comercial.

CCDR Algarve. Comissão de Coordenação e Desenvolvimento Regional do Algarve (2006). Estratégia de Desenvolvimento do Algarve 2007-2013. Faro: SIG.

Coriolano, Luzia Neide M. T. (2009). Arranjos produtivos locais do turismo comunitário: atores e cenários em mudanças. Fortaleza: EDUECE.

Costa, Carlos, Brandão, Felipa, Costa, Rui, \& Breda, Zélia. (2014). Turismo nos países lusófonos: conhecimento, estratégia e territórios. Lisboa: Escolar.

Cravidão, Fernanda. (2014). Velho (s) território(s): novo(s) turismo(s). In Costa, Carlos, Brandão, Felipa, Costa, Rui, \& Breda, Zélia. Turismo nos países lusófonos: conhecimento, estratégia e territórios. Lisboa: Escolar, 59-69.

Cunha, Licínio. (2001). Introdução ao turismo. Lisboa: Editorial Verbo.

Daveau, S. (1995). Portugal geográfico. Lisboa: Edições João Sá da Costa.

Diário Online de Algarve. (2014, 19 de julho). Turismo criativo e cultural cresce no Algarve em alternativa ao turismo massificado. Diário Online (Algarve), p. 1. Recuperado de www.regiao-sul.pt

Fayos-Solà, Eduardo, \& Jafari, Jafar. (2009). Cambio climático y turismo: realidad y ficción. Valencia: Publicaciones de la Universidad de Valencia.

Ferreira, Ana Maria. (2014). Turismo como fato de regeneração e desenvolvimento de meios urbanos e rurais: do turismo cultural ao turismo criativo. In Costa, Carlos, Brandão, Felipa, Costa, Rui, \& Breda, Zélia. Turismo nos países lusófonos: conhecimento, estratégia e territórios. Lisboa: Escolar.

Hovinen, Gary R. (2006). Lancaster County, the TALC, and the search of sustainable tourism. In Butler, Richard W. Aspects of tourism - the tourism área life cycle: applications and modifications. Clevedon: Channel View.

INE. Instituto Nacional de Estatísticas. (2014). Censo 2011. Recuperado de censos.ine.pt

Lefebvre, Henri. (1991). A vida cotidiana no mundo moderno. São Paulo: Ática.

Matos, Patrícia Francisca de, \& Pessôa, Vera Lúcia Salazar. (2009). Observação e entrevista: construção de dados para pesquisa qualitativa em geografia agrária. In: Ramires, Júlio César de Lima, \& 
Pessôa, Vera Lúcia Salazar. Geografia e pesquisa qualitativa: nas trilhas da investigação. Uberlândia: Assis.

Medina, N., \& Santamarina, J. (2004) Turismo de naturaleza en Cuba. Havana: Unión.

Pessoa, F. S., Bernardes, J. P., Correia, J. E., Costa, M. R., \& Guerreiro, J. P. (2005). Algarve Visto do Céu. Lisboa: Edições Argumentum.

Pires, Paulo dos Santos, Anjos, Francisco A., Oliveira, Josildete Pereira de, \& Silva, Yolanda Flores e. (2009, janeiro/abril). Estruturação de matriz de impactos do turismo: o caso do agroturismo no município de Santa Rosa de Lima/SC. Revista Brasileira de Pesquisa em Turismo, 3(1), 68-89.

Ribeiro, Orlando. (1986). Portugal - o Mediterrâneo e o Atlântico. (4a ed.). Lisboa: Livraria Sá da Costa.

Richards, G. W. (2011). Creativity and tourism: the state of the art. Proceedings of Tourism Research, 38(4), 1225-1253.

Santos, J. C. V. (2013). Região e destino turístico: sujeitos sensibilizados na geografia dos lugares. São Paulo: Allprint.

Santos, Jean Carlos Vieira \& Silva, Débora Cristina Barbosa da. (2016). Engenho urbano: reflexões sobre o caso Riverlândia (Goiás). Revista Tocantinense de Geografia, 5(7), 105-119, jan./jul.

Santos, Jean Carlos Vieira \& Silva, João Albino. (2015). A arte da olaria no turismo da região Algarve, Portugal. Revista Turismo - Visão e Ação, 17(3), 658-690, set./dez.

Santos, Maria da Graça Mouga Poças. (2006). Espiritualidade, turismo e território. Estoril: Principia.

Santos, Rossel Monteiro. (2011). Histórico do Concelho de Lagoa. Lisboa: Colibri Artes Gráficas.

Silva, M. E. M., \& Soriano-Sierra, E. J. (2015). Análise da percepção do visitante sobre a revitalização da orla marítima: o modelo do Parque Linear Calçadão, Itapema - Santa Catarina - Brasil. Revista Brasileira de Pesquisa em Turismo, 9(1), 76-96, jan./abr.

Trigo, Luiz Gonzaga G. (2013). A viagem: caminho e experiência. São Paulo: Aleph.

Yázigi, Eduardo. (1998). Turismo: uma esperança condicional. São Paulo: Plêiade.

Zuin, Poliana Bruno, \& Zuin, Fernando Soares. (2009). Tradição e alimentação. Aparecida: Ideias \& Letras.

Artigo recebido em: 30/11/2015.

Artigo aprovado em: 20/04/2016. 